\title{
ESCAVAÇÃO NA ÁREA ARQUEOLÓGICA DO SERIDÓ O Sítio Furna do Umbuzeiro, Carnaúba dos Dantas, Rio Grande do Norte, Brasil
}

\section{EXCAVATION ON AN ARCHAEOLOGICAL AREA OF SERIDÓ: \\ Furna do Umbuzeiro Site, Carnaúba dos Dantas, Rio Grande do Norte, Brazil}

\author{
Adriano Campelo \\ adrianocampelorn@hotmail.com \\ Diógenes Santos Saldanha ${ }^{1}$ \\ diogenes.saldanha@hotmail.com \\ Fabio Mafra ${ }^{2}$ \\ fabiomafraborges@gmail.com \\ Gabriela Martin ${ }^{3}$ \\ gabrielamartinavila@gmail.com
}

\author{
Henrique Roque Dantas ${ }^{4}$ \\ hrdantas@yahoo.com.br \\ Joadson Vagner Silva ${ }^{5}$ \\ joadsonvagnersilva@gmail.com \\ Marcellus de Almeida ${ }^{4}$ \\ marcellus85@gmail.com \\ Mizael Manoel Santos da Costa ${ }^{1}$ \\ mizaelscosta16@gmail.com \\ Mônica Nogueira ${ }^{1}$ \\ monica.aan@gmail.com
}

\section{RESUMO}

Este artigo descreve as intervenções arqueológicas realizadas na terceira escavação do sítio Furna do Umbuzeiro no ano de 2016. A relação entre o estado e a distribuição espacial das estruturas de combustão e dos remanescentes ósseos humanos e não humanos pode ser um indício da prática de canibalismo.

Palavras-chave: Furna do Umbuzeiro; Intervenções arqueológicas; Carnaúba dos Dantas.

${ }^{1}$ Discente, Departamento de História, CERES, UFRN.

${ }^{2}$ Departamento de História, CERES/UFRN.

${ }^{3}$ Docente, Programa de Pós-Graduação em Arqueologia, UFPE.

${ }^{4}$ Geografo autônomo.

${ }^{5}$ Discente, Programa de Pós-Graduação em Arqueologia, UFPE.

Indexadores: Latindex, ISIS, Google Academic 


\section{ABSTRACT}

This article describes the archaeological interventions carried out in the third excavation of the Furna do Umbuzeiro site in 2016. The relationship between the state and the spatial distribution of combustion structures and human and nonhuman bone remnants may be an indication of the practice of cannibalism.

Keyword: Furna do Umbuzeiro; Archaeological interventions; Carnaúba dos Dantas.

\section{O SÍTIO ARQUEOLÓGICO FURNA DO UMBUZEIRO}

O presente artigo tem por objetivo apresentar as intervenções arqueológicas realizadas no mês de setembro, do ano de 2016, no sítio Furna do Umbuzeiro, Carnaúba dos Dantas - RN. As pesquisas estão vinculadas ao Projeto Seridó: Metrologia e Escavações Arqueológicas ${ }^{6}$, coordenado pela Profa. Dra. Gabriela

Martin do Programa de Pós-Graduação em Arqueologia da Universidade Federal de Pernambuco.

A partir do ano de 2007 começam a ser registrados sítios a céu aberto, bem como um sítio em abrigo sob rocha sem a presença de registros rupestres, na área arqueológica do Seridó. Isso difere do padrão de assentamento estabelecido para a região, até então definido como ritualístico, relacionado a sítios com vestígios de práticas funerárias e/ou gráficas (MARTIN, 2008; BORGES, 2010). Este novo conjunto de sítios arqueológicos pode estar relacionado a um padrão de assentamento distinto: os espaços habitacionais. Tal temática é objetivo de uma

${ }^{6}$ O projeto conta com o financiamento do Instituto Nacional de Ciência e Tecnologia de Arqueologia, Paleontologia e Ambiente do Semiárido do Nordeste do Brasil (INCT - INAPAS) e com o apoio logístico da Fundação Seridó. 
das linhas do projeto de pesquisa supracitado e já rendeu alguns trabalhos publicados (ver MARTIN, et al., 2008; BORGES, 2008; BORGES, 2010; NOGUEIRA, MAFRA, 2014; MAFRA, MARTIN, NOGUEIRA, 2015; MAFRA, MARTIN, NOGUEIRA, 2016).

Um dos sítios identificados foi a Furna do Umbuzeiro; um abrigo rochoso com dimensões de $14,40 \mathrm{~m}$ de comprimento por $6,10 \mathrm{~m}$ de profundidade e área habitável de aproximadamente $80 \mathrm{~m}^{2}$ (BORGES, 2010). Formado por rochas sedimentares metamorfizadas (biotita xistos) - pertencentes à Formação Seridó encontra-se localizado no sopé da Serra Nova, aproximadamente $170 \mathrm{~m}$ da margem esquerda do Riacho das Areias, na localidade Lajedo, em Carnaúba dos Dantas (Figura 1, Figura 2) (IDEMA, 2008; BORGES, 2010).

Quanto à hidrografia, o Riacho das Areias é tributário do Rio da Cobra, afluente da margem direita do Rio Seridó que por sua vez faz parte da Bacia Hidrográfica do Rio Piranhas-Açu. Tal corpo hídrico caracteriza-se por cursos d'água temporários, que ocorrem apenas no período chuvoso (SUDENE, 1985; IDEMA, 2008; ANA, 2010).

A vegetação no entorno do abrigo é do tipo xerófila: caatinga característica do sertão nordestino (AB'SÁBER, 2003) (Figura 1; Figura 2). As espécies vegetais são do tipo caducifólio. Predominando, entre as arbóreas, a baraúna (Schinopsis brasilienses), a jurema-branca (Mimosa arenosa), a jurema-preta (Mimosa 
tenuiflora), o marmeleiro (Croton sonderianius), o mofumbo (Combretum leprosum), o mororó (Bauhinia ungulata), o pinhão-branco (Jatropha mollissima), a umburana (Commiphora leptophloeos), o umbuzeiro (Spondia tuberosa), além de uma espécie de árvore exótica, a algarobeira (Prosopis juliflora).

Entre os arbustos, são encontrados a malva-branca (Sida cordifolia L.), o melabode (Herissan tiatiubae) e o velame (Croton heliotropiifolius). Das cactáceas tão comuns à caatinga - encontram-se no entorno da Furna do Umbuzeiro, a gogóia (Tacinga inamoena), o facheiro (Piloscereus pachycladus) e o xiquexique (Pilosocerus polygonus) e $\mathrm{m}$ tipo de bromeliácea, a macambira (Bromelia laciniosa). Além dos espécimes acima citados, há no entorno do sítio, também, uma ampla variedade de gramíneas e outras plantas rasteiras típicas da caatinga.

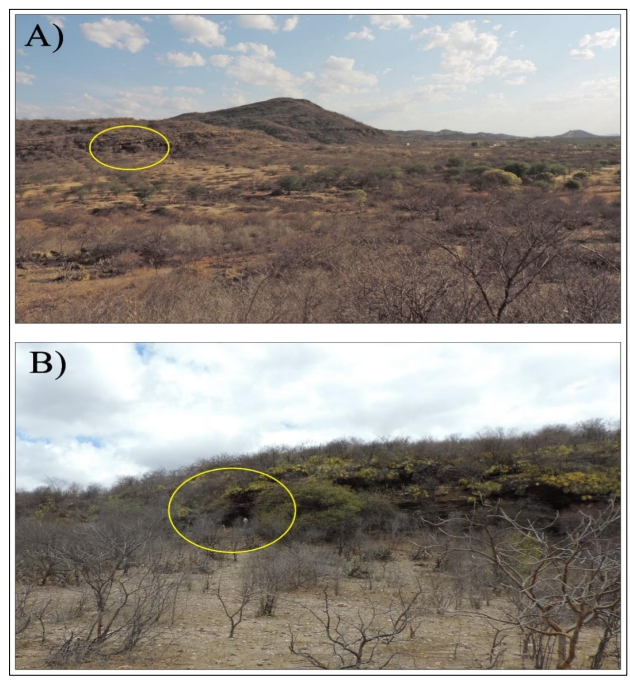

Figura 1: Sítio Furna do Umbuzeiro, apontado pelos círculos amarelos. A) Vista geral do vale do riacho das Areias, com o abrigo rochoso no sopé da Serra Nova; B) vista da entrada do abrigo. 


\section{ANTECEDENTES ARQUEOLÓGICOS: CAMPANHAS ANTERIORES}

$\mathrm{Na}$ Furna do Umbuzeiro, foram realizadas três campanhas arqueológicas: a primeira em agosto de 2007, a segunda em dezembro de 2008 e a terceira em setembro de 2016, objeto de descrição deste artigo.

Em agosto 2007, houve a identificação e registro da Furna do Umbuzeiro. O mesmo foi encontrado graças a uma toca de tatu (Euphractuss excinctus s.p.) que expôs uma parte da estratigrafia do sítio, composta por lentes de cinzas e carvões; além de trazer a superfície materiais cerâmicos e líticos (MARTIN, et al., 2008; BORGES, 2010) (Figura 2). No mesmo período, ocorreu a primeira escavação. Inicialmente, com o objetivo de controle quanto ao registro dos vestígios arqueológicos, o sítio foi dividido em quadrículas de $1 \mathrm{~m}^{2}$, orientadas por eixos alfanuméricos (BORGES, 2010).

A área selecionada para as intervenções arqueológicas foi aquela correspondente a porção central do abrigo, na qual foi registrada uma maior concentração de vestígios e atividades de combustão. Dessa maneira, foram realizadas decapagens artificiais de $5 \mathrm{~cm}$, divididas em decapagem inicial $(2,5 \mathrm{~cm})$ e final $(2,5 \mathrm{~cm})$, respeitando o comportamento das estruturas arqueológicas registradas. As quadrículas escavadas foram: 
1. H1: 11 (onze) decapagens, $55 \mathrm{~cm}$ de profundidade;

2. H3: 02 (duas) decapagens em $70 \mathrm{~cm}$ da quadrícula, resultando em uma profundidade de $10 \mathrm{~cm}$; além de 03 (três) decapagens nos $30 \mathrm{~cm}$ restantes - para evitar o desmoronamento do perfil Leste da quadrícula I3;

3. H5: 02 (duas) decapagens, $10 \mathrm{~cm}$ de profundidade;

4. I4: 01 (uma) decapagem $(5 \mathrm{~cm})$, em $30 \mathrm{~cm}$ da área delimitada, para evitar o desmoronamento do perfil Norte da quadrícula I3);

5. I5: 02 (duas) decapagens, atingindo uma profundidade de $10 \mathrm{~cm}$ );

6. I3: 18 (dezoito) decapagens, profundidade de $90 \mathrm{~cm}$.

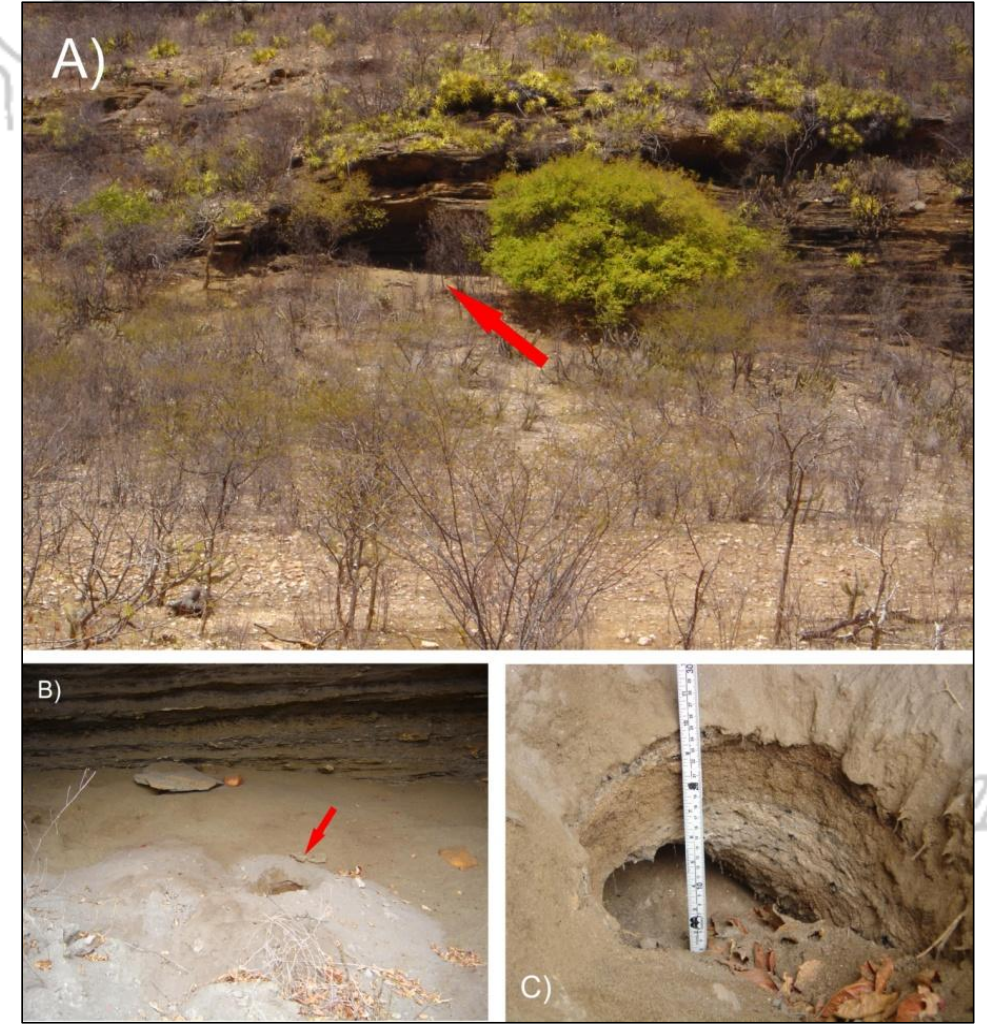

Figura 2: Imagens do sítio arqueológico Furna do Umbuzeiro, Carnaúba dos Dantas/RN. (A) Vista geral do abrigo; (B) área abrigada do sítio arqueológico; (C) detalhe de perturbação biológica de sedimento (toca de tatu-Euphractus excinctus s.p.). 
Os vestígios evidenciados na primeira campanha foram estruturas de combustão formadas por uma sequência de dezessete (17) fogueiras de tipologia similar, superpostas na área central do abrigo; remanescentes ósseos não humanos, com marcas de queima; remanescentes ósseos humanos, associados aos ossos faunísticos e às estruturas de combustão; restos vegetais naturais com ou sem indícios de queima; fibras vegetais retorcidas, sobrepostas e trançadas, possivelmente para confecção de cestos, cordéis e esteiras; fragmentos cerâmicos com tratamento de superfície alisado, polido, pintado e brunido; material lítico lascado e com marcas de alisamento; e fezes mumificadas humanas e não humanas, (BORGES, 2010).

\begin{tabular}{|c|c|c|c|c|}
\hline $\begin{array}{c}\text { REFERÊNCIA } \\
\text { (ETIQUETA E } \\
\text { PONTO } \\
\text { TOPOGRÁFICO) }\end{array}$ & $\begin{array}{c}\text { DECAPAGEM } \\
\text { E } \\
\text { QUADRÍCULA }\end{array}$ & $\begin{array}{c}\text { CÓDIGO } \\
\text { LABORATORIO }\end{array}$ & $\begin{array}{l}\text { EDAD C-14 } \\
\text { CONVENCIONAL } \\
\text { (años BP) }\end{array}$ & $\begin{array}{l}\text { EDAD } \\
\text { CALIBRADA } \\
\text { (años cal BP) }\end{array}$ \\
\hline ET $244-$ PT 449 & $\begin{array}{c}\text { Dec. } 9 \\
(45 \mathrm{~cm}) \\
\text { Quadricula I3 }\end{array}$ & CSIC-2097 & $3630 \pm 32$ & $\begin{array}{c}3980-3810 \\
(82,4 \%) \\
3800-3720 \\
(13,0 \%)\end{array}$ \\
\hline ET $259-$ PT 446 & $\begin{array}{c}\text { Dec. } 9 \\
(45 \mathrm{~cm}) \\
\text { Quadricula I3 }\end{array}$ & CSIC- 2143 & $3170 \pm 40$ & $\begin{array}{c}3450-3210 \\
(95,4 \%)\end{array}$ \\
\hline ET 177 - PT 387 & $\begin{array}{c}\text { Dec. } 6 \\
(30 \mathrm{~cm}) \\
\text { Quadricula I3 }\end{array}$ & CSIC- 2148 & $2804 \pm 40$ & $\begin{array}{c}2950-2760 \\
(95,4 \%)\end{array}$ \\
\hline ET $146-$ PT 378 & $\begin{array}{c}\text { Dec. } 5 \\
(25 \mathrm{~cm}) \\
\text { Quadricula I3 }\end{array}$ & CSIC-2098 & $2666 \pm 30$ & $\begin{array}{c}2800-2700 \\
(90,1 \%) \\
2640-2610(4,1 \%) \\
2580-2540(1,3 \%) \\
\end{array}$ \\
\hline ET $64-$ PT 230 & $\begin{array}{c}\text { Dec. 1 } \\
(5 \mathrm{~cm}) \\
\text { Quadricula I3 }\end{array}$ & CSIC- 2210 & $1775 \pm 31$ & $\begin{array}{c}1710-1540 \\
(95,4 \%)\end{array}$ \\
\hline ET $63-$ PT 229 & $\begin{array}{l}\text { Dec. } 1 \\
(5 \mathrm{~cm}) \\
\text { Quadrícula I3 }\end{array}$ & CSIC-2093 & $1316 \pm 28$ & $\begin{array}{c}1290-1080 \\
(95,4 \%)\end{array}$ \\
\hline ET $216-$ PT 231 & $\begin{array}{c}\text { Dec. } 1 \\
(5 \mathrm{~cm}) \\
\text { Quadricula I4 }\end{array}$ & CSIC-2094 & $1315 \pm 28$ & $\begin{array}{c}1290-1080 \\
(95,4 \%)\end{array}$ \\
\hline
\end{tabular}

Figura 3: Tabela com as datações para o sítio arqueológico Furna do Umbuzeiro, Carnaúba dos Dantas - RN (Laboratório de Geocronologia do Instituto de Química-Física de Rocasolano, Espanha). Fonte: BORGES, 2010, p. 24. 
A coleta de amostras de carvão das estruturas de combustão permitiu estabelecer uma cronoestratigrafia para o sítio de $3630 \pm 32$ B.P. a $1315 \pm 28$ B.P., obtida a partir de datações por radiocarbono, (Figura 3), (BORGES, 2010).

Os remanescentes ósseos humanos se caracterizaram por estarem em estado fragmentado e/ou disperso, identificados quase sempre relacionados a estruturas de combustão e a ossos não humanos. Estes indícios, fora de contextos funerários, não puderam ser interpretados como inumações identificáveis, nesses primeiros níveis escavados (BORGES, 2008; BORGES, 2010).

No sítio, um dos fragmentos cerâmicos encontrados possui a datação mais antiga para esse tipo de material na área arqueológica do Seridó. $O$ fragmento de cerâmica em questão, estava relacionado a uma estrutura de combustão - Fogueira 9 - que foi datada em \pm 2700 B.P., e não apresentou indícios de percolação estratigráfica. Tal achado proporcionou um recuo no registro da presença da tecnologia cerâmica na região de quase mil anos, (BORGES, 2010).

Na primeira campanha, foi ainda demonstrado que o sítio possui um pacote sedimentar com níveis arqueológicos a uma profundidade superior a $85 \mathrm{~cm}$, como foi verificado na quadrícula I3. A partir da profundidade de $65 \mathrm{~cm}$ (decapagem 13) até os $75 \mathrm{~cm}$ (decapagem 15) foi registrada uma camada estéril, sem vestígios de atividades de combustão. Os raros vestígios arqueológicos identificcados estavam relacionados a áreas de percolação estratigráficas e perturbação 
sedimentar. Após esse nível estéril, em $85 \mathrm{~cm}$ (decapagem 17), foram encontradas mais duas estruturas de combustão, configurando um nível de ocupação com cronologias recuadas. Dada a baixa compactação do sedimento constituinte da área escavada, optou-se pela remoção completa dos primeiros níveis arqueológicos do abrigo, antes da realização de decapagens nessa profundidade registrada, (BORGES, 2010).

A segunda campanha foi realizada em dezembro de 2008. Teve como objetivo "identificar níveis de ocupação preservados, para corroborar ou refutar o que foi verificado na primeira campanha", (BORGES, 2010, p. 164). Para tanto, escavouse a área central do abrigo, porção com maior incidência de vestígios e estruturas arqueológicas, em superfície ampla, visando uma melhor definição horizontal dos níveis de ocupação registrados, (BORGES, 2010).

No processo de escavação foram mantidas as decapagens artificiais de $5 \mathrm{~cm}$, com a decapagem inicial $(2,5 \mathrm{~cm})$ e final $(2,5 \mathrm{~cm})$. As quadrículas escavadas foram aquelas adjacentes a quadrícula I3: quadrícula I2, quadrícula I4, quadrícula J2, quadrícula J3 e quadrícula J4. Em todas foram realizadas 5 decapagens, as quais atingiram uma profundidade de $25 \mathrm{~cm}$. Além disso, foi aberta uma sondagem nas quadrículas L2 (quadrante 4, 02 (duas) decapagens, até uma profundidade de 20 $\mathrm{cm}$ ) e L3 (quadrante 1, também 02 (duas) até $20 \mathrm{~cm}$ de profundidade $\mathrm{cm}$ ), para que as fibras vegetais manipuladas pudessem ser coletadas, (BORGES, 2010). 
Os vestígios identificados foram: (a) 05 (cinco) estruturas de combustão, além de porções de outras fogueiras parcialmente escavadas durante a primeira campanha; (b) manchas húmicas isoladas e em associação com materiais cerâmicos e líticos ou localizadas na base das estruturas de combustão; (c) ossos não humanos, alguns na base de estruturas de combustão e com sinais de queima; (d) restos vegetais naturais; (e) fibras vegetais manipuladas; (f) fragmentos cerâmicos, alguns associados às estruturas de combustão; (g) materiais líticos; (h) remanescentes ósseos humanos encontrados na base da fogueira 18 , sem indícios de perturbação ou percolação estratigráfica; (i) fezes mumificadas não humanas diferentemente da primeira campanha, nesta não foram encontradas fezes mumificadas de origem humana (BORGES, 2010). Nas duas campanhas realizadas, em 2007 e 2008, não foram registradas estruturas funerárias que pudessem estar relacionadas aos remanescentes ósseos humanos identificados. Este fato condicionou duas possibilidades distintas de interpretação:

1) Perturbação do pacote sedimentar por agentes antrópicos ou naturais, que possivelmente teriam ocasionado percolação vertical ascendente dos ossos humanos oriundos de níveis inferiores, nos quais haveria a presença de estruturas funerárias ainda não identificadas;

2) O registro de práticas canibais, na medida em que a presença de um número reduzido de ossos humanos e sua relação, na maior parte das vezes, com estruturas de combustão e em associação direta com remanescentes ósseos não humanos - em ambos os casos com marcas de queima - pode subsidiar esta interpretação. Nesse sentido, o contexto deposicional identificado pode ser o resultado de atividades relacionadas ao processamento de tecidos humanos para o consumo. 


\section{TERCEIRA CAMPANHA ARQUEOLÓGICA}

A terceira campanha arqueológica no sítio Furna do Umbuzeiro ocorreu no mês de setembro de 2016. Os objetivos almejados com a intervenção arqueológica foram: a) ampliar a área escavada do abrigo, tanto horizontalmente, quanto verticalmente; b) identificar outros níveis de ocupação preservados; e, c) aumentar a amostra laboratorial de remanescentes humanos: fezes mumificadas e ossos. Este procedimento buscou verificar se os remanescentes ósseos encontrados no interior das estruturas de combustão eram decorrentes de perturbações de níveis estratigráficos mais antigos ou resquícios de alterações antrópicas de ossos humanos. Para tanto, deu-se continuidade a escavação das quadrículas adjacentes à quadrícula I3 - área de maior incidência de remanescentes ósseos e fezes mumificadas, escavada ainda na primeira campanha.

Portanto, as quadrículas selecionadas, na campanha de 2016, foram: quadrícula $\mathrm{H} 2$, quadrícula H3, quadrícula I2, quadrícula J2, quadrícula J3. Além dessas, foi também realizada a escavação da quadrícula O4 (Figura 4). 


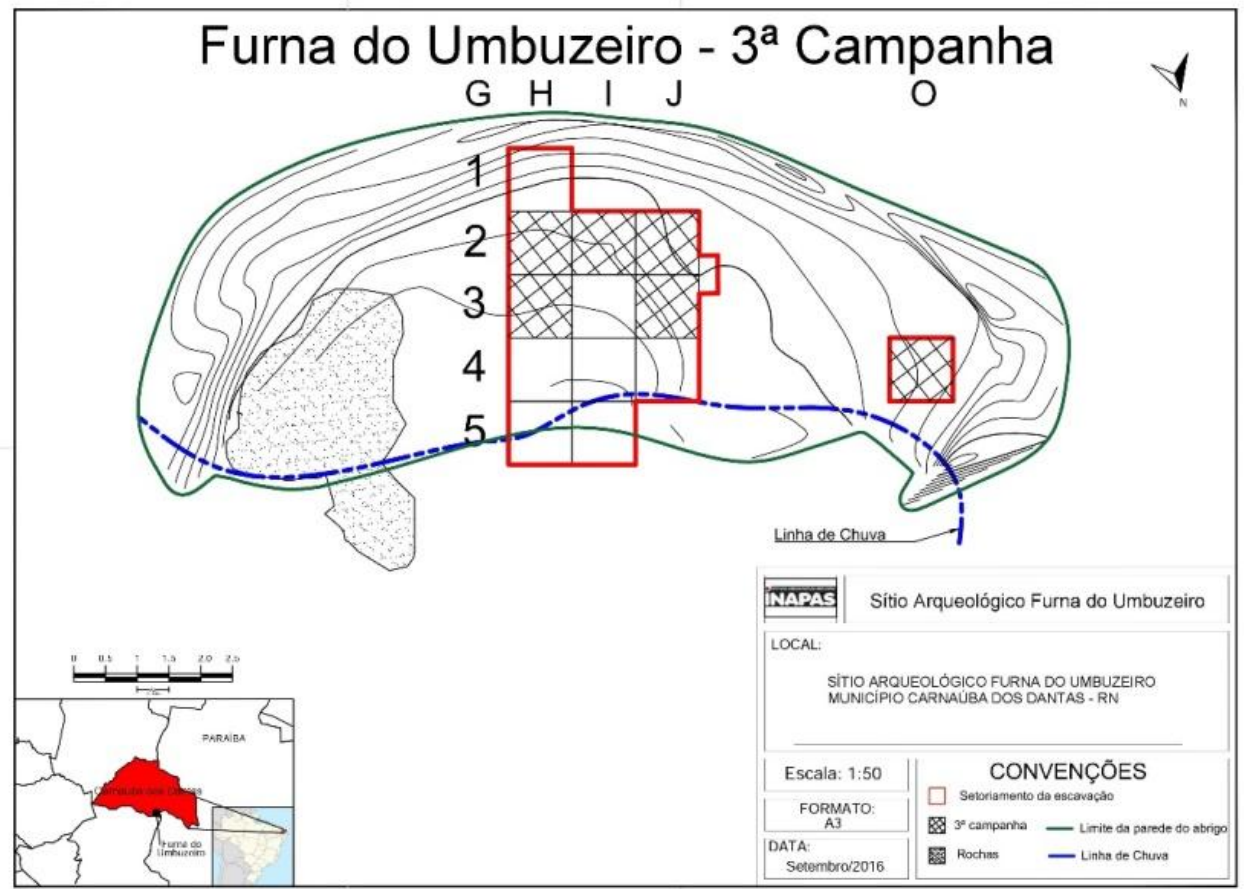

Figura 4: Mapa de representação da área escavada na terceira campanha arqueológica no sítio Furna do Umbuzeiro, setembro de 2016.

\section{METODOLOGIA E INTERVENÇÕES ARQUEOLÓGICAS}

Os procedimentos realizados na terceira campanha da Furna do Umbuzeiro foram:

1) Escavação na área central do abrigo rochoso. Abertura da quadrícula $H 2$, não escavada. Continuação das atividades realizadas nas quadrículas H3, I2, J2 e J3;

2) Escavação da quadrícula O4, no setor oeste do sítio, área não escavada;

3) Registro topográfico dos níveis escavados, da parede rochosa do abrigo, bem como do seu entorno; 
4) Registro fotográfico e gráfico (desenho) dos níveis e estruturas evidenciados.

5) Coleta e registro topográfico da distribuição dos vestígios arqueológicos identificados em superfície e nos níveis escavados.

A metodologia das decapagens foi mantida, com a realização de decapagens artificiais de $5 \mathrm{~cm}$, cada qual dividida em inicial $(2,5 \mathrm{~cm})$ e final $(2,5 \mathrm{~cm})$, em respeito ao comportamento estratigráfico das estruturas arqueológicas identificadas. À medida que as estruturas de combustão (fogueiras) foram sendo evidenciadas, eram deixadas em pedestal para melhor visualização e registro.

$\mathrm{Na}$ quadrícula $\mathrm{H} 2$, que não havia sido aberta, foi escavada até a decapagem 2 inicial (profundidade de 7,5 cm). As quadrículas que continuaram sendo escavadas foram: $\mathrm{H} 3$, até a decapagem 9 (profundidade de $45 \mathrm{~cm}$ ); I2, finalizando na decapagem $7(35 \mathrm{~cm}) ; \mathrm{J} 2$, escavada até a decapagem 9 (profundidade de 45 $\mathrm{cm}$ ) e a J3, até a decapagem 7 (profundidade de $35 \mathrm{~cm}$ ).

A quadrícula $\mathrm{O} 4$, localizada no setor oeste do abrigo, apesar de não fazer parte porção central do sítio - onde a escavação demonstrou maior incidência de vestígios arqueológicos - foi selecionada para abertura de uma sondagem. Além de se encontrar em uma área propicia a ocupação humana, no teto rochoso do abrigo, sobre a área selecionada, foi registrada a presença de uma densa mancha de fuligem, que sugeriu a presença de estruturas de combustão soterradas. Nesta foram realizadas nove (09) decapagens (profundidade $45 \mathrm{~cm}$ ), sendo mantidas as decapagens de $5 \mathrm{~cm}$, divididas em 2,5 $\mathrm{cm}$ (decapagem inicial e decapagem final). 
A descrição dos vestígios identificados segue abaixo, ressaltando que todo sedimento movimentado, passou por uma peneira de malha fina $(<0,5 \mathrm{~cm})$, a fim de evitar a perda de materiais de importância arqueológica.

\section{Vestígios identificados}

Na terceira campanha no abrigo Furna do Umbuzeiro, com a ampliação horizontal da área escavada, os vestígios identificados apresentaram a mesma tipologia daqueles encontrados nas campanhas anteriores. Tal fato confirmou a preservação do contexto deposicional na área escavada. As estruturas de combustão, que tanto eram delimitadas por rochas endógenas do abrigo (micaxisto e blocos de quartzo), como exógenas (gnaisse), com fragmentos de carvão e cinzas - ou somente contendo cova com esses últimos materiais - foram o principal vestígio arqueológico identificado. A estas fogueiras estão associados a maior parte dos outros vestígios da presença humana registrados no sítio, a saber:

1. Remanescentes posseos não humanos, completos e/ou fragmentados, alguns dos quais com marcas de combustão;

2. Restos vegetais naturais: vegetação do entorno direto ao abrigo (cascas, folhas, galhos, madeira e sementes);

3. Restos vegetais: fibras manipuladas (Figura 5, Figura 6, Figura 7);

4. Fragmentos de conchas de gastrópodes queimadas;

5. Fragmentos de material cerâmico com tratamento de superfície alisado, pintado e polido;

6. Material lítico lascado; 
7. Remanescentes ósseos humanos, fragmentados ou completos de pequenas dimensões (falanges), alguns dos quais com indícios de queima (Figura 8, Figura 9);

8. Fezes mumificadas não humanas.

As fogueiras identificadas nas duas campanhas anteriores, que nestes períodos não foram totalmente escavadas, devido ao fato de terem sido evidenciadas nos perfis, ou por que elas se localizavam logo abaixo do nível das últimas decapagens realizadas, são: Fogueira 14, Fogueira 17, Fogueira 18 e Fogueira 22. Na terceira campanha estas estruturas foram completamente escavadas.

1) Fogueira 17 (Figura 10, Figura 11): identificada na quadrícula $\mathrm{H3}$, ainda na primeira campanha, localizava-se desde a junção entre os perfis Sul e Oeste, até o centro da quadrícula. Nesta fogueira, foram registrados uma mancha de cinza e fragmentos de carvão, associados a um sedimento de coloração branca que aumentou, à medida que se chegava a base da estrutura. Este sedimento pode ser proveniente da combustão de matéria-prima de origem vegetal ou oriunda da queima de materiais orgânicos, ricos em cálcio (ex.: ossos ou conchas);

2) Fogueira 18 (Figura 12): identificada na quadrícula J3, na segunda campanha. Na terceira campanha foi registrada somente a base da estrutura, que se encontrava próxima ao encontro dos perfis Sul e Leste. A fogueira apresentava uma mancha de cinzas com fragmentos de carvão e duas manchas de sedimento amarelado, com tonalidades diferentes, resultante das atividades de combustão realizadas sobre o solo;

3) Fogueira 22 (Figura 12): evidenciada também na segunda campanha, na quadrícula J3; na terceira campanha foi registrada somente a base da estrutura, localizada próximo ao perfil Norte, penetrando nos sedimentos da 
quadrícula J4. A estrutura registrada apresentava uma mancha de cinzas e fragmentos de carvão (em menor quantidade que as Fogueiras 18 e 24), delimitada por blocos de quartzo. Na quadrícula J3, foi encontrada próxima a fogueira 22 uma falange humana em meio às cinzas, que pela proximidade da estrutura podia estar relacionada a esta, tendo carreado para fora e mantendo-se no mesmo nível (Figura 9).

Além da continuação da escavação de fogueiras identificadas nas duas campanhas anteriores, nesta campanha foram registradas mais cinco (5) estruturas de combustão: Fogueira 23, Fogueira 24, Fogueira 25, Fogueira 26 e Fogueira 27, as quais foram escavadas. Ressalta-se que, em todas as estruturas, coletaram-se amostras de carvão para possíveis datações radiocarbônicas, apesar cronoestratigrafia dos níveis escavados, já haver sido definida com as intervenções realizadas nas duas campanhas anteriores:

1) Fogueira 23 (Figura 10, Figura 11): identificada na quadrícula $\mathrm{H} 3$, desde o encontro dos perfis Sul e Oeste, até o centro da quadrícula, decapagem 3 (final $\pm 15 \mathrm{~cm})$. Era uma estrutura em cova $(40 \mathrm{~cm})$, composta por fogueiras sobrepostas, indicando vários momentos de atividades de combustão. Continha uma mancha de cinza e fragmentos de carvão. Na base dessa estrutura foi registrado um fragmento de cerâmica, há aproximadamente 45 $\mathrm{cm}$ de profundidade na decapagem 9 (final);

2) Fogueira 24 (Figura 12): evidenciada na quadrícula J3, junto ao perfil Oeste, decapagem 5 (final $\pm 25 \mathrm{~cm}$ ). A estrutura apresentou sedimento acinzentado com fragmentos de carvão. Próximo aos limites da estrutura de combustão, no mesmo nível, foi registrado um fragmento de costela humana (Figura 8), com indicativo de alteração cromática, e um fragmento ósseo não humano, ambos com indícios de queima; 
3) Fogueira 25 (Figura 13): identificada na quadrícula J2, próximo ao encontro entre os perfis Sul e Leste, decapagem 8 (inicial $\pm 37,5 \mathrm{~cm}$ ). Caracterizavase por estar delimitada por blocos de micaxisto endógenos $( \pm 5 \times 12 \mathrm{~cm})$, que formavam a estrutura. Continha, além de fragmentos de carvão e cinzas, fibras vegetais manipuladas. Estas últimas compunham um fragmento de cestaria que estava associado a sementes, fragmentos de madeira e ossos não humanos carbonizados. A cestaria encontrava-se depositada sobre a estrutura de combustão e apresentava indícios de chamuscamento. Entretanto, a fibra vegetal ficou conservada, demonstrando que foi depositada quando o fogo estava brando;

4) Fogueira 26 (Figura 14): identificada no centro da quadrícula J2, próximo ao encontro dos perfis Norte e Leste, decapagem 9 (final $\pm 45 \mathrm{~cm}$ ). Continha, além de fragmentos de carvão e cinzas, sementes (inclusive, algumas queimadas), fragmentos de madeira, um fragmento ósseo humano, ossos não humanos, fragmentos de cordel e fragmentos de concha de gastrópodes. Foi verificada a presença, sobre a fogueira 26, de fragmentos de cestaria com indícios de chamuscamento, o que demonstra, tal qual na fogueira 25 , que o material foi depositado quando o fogo estava brando;

5) Fogueira 27 (Figura 11): foi identificada na quadrícula H3, decapagem 4 (inicial $\pm 17,5 \mathrm{~cm}$ ). Localizava-se no perfil Sul, junto ao perfil Leste. Devido ao fato dessa estrutura está localizada quase que inteiramente na quadrícula $\mathrm{H} 2$, não passou por intervenção na terceira campanha. Foi mantida preservada no sítio já que a quadrícula $\mathrm{H} 2$ somente foi escavada até a profundidade de $10 \mathrm{~cm}$, em decorrência da pouca ocorrência de vestígios; 


\section{CONSIDERAÇÕES FINAIS}

Os dados provenientes da terceira campanha no sítio Furna do Umbuzeiro, relacionados àqueles oriundos das campanhas arqueológicas anteriores, serão utilizados na tentativa de identificação da prática mortuária que originou os fragmentos ósseos registrados no abrigo.

O estado em que foram identificados os remanescentes ósseos humanos na Furna do Umbuzeiro indica que os mesmos podem ser vestígios de indivíduos processados para ingestão. Foi encontrado apenas uma porção mínima do esqueleto, o que, partindo de exemplos conhecidos e fazendo-se analogia indireta, pode indicar o consumo não só das partes brandas, mas inclusive dos ossos dos indivíduos. O caso dos atuais Yanomami, habitantes de uma área entre o Brasil e a Venezuela (CLASTRES, 2004; RAMALHO, 2008) e dos Tarairiú, que ocupavam áreas dos atuais estados do Ceará, Rio Grande do Norte e Paraíba (MEDEIROS FILHO, 1984), é bem elucidativo quanto a esse processo ritualístico. Estes dois grupos são/eram caracterizados por possuir um ritual funerário que procura/procurava não deixar vestígios materiais. Em ambos os grupos, os familiares consomem/consumiam os ossos de seus mortos, depois que esses são/eram calcinados e pulverizados, o que, a não ser em marcadores proteicos presentes nas fezes (material difícil de ser registrado), não deixa/deixava evidências tangíveis que possam servir para análises arqueológicas. 
Apesar da quantidade reduzida de remanescentes humanos identificados, um dos principais vestígios evidenciados foi um fragmento ósseo humano com indicativo de alteração cromática avermelhada (identificado na quadrícula $\mathrm{H} 3, \mathrm{em} \pm 30 \mathrm{~cm}$ de profundidade) (Figura 8). Este achado gerou dúvidas acerca da hipótese de práticas canibais. Enquanto os ossos fragmentados encontrados no interior das estruturas de combustão, relacionados a ossos não humanos, sugerem esta prática, a probabilidade de haver vestígios de pigmentação nesse fragmento ósseo, fortalece a possibilidade de enterramentos secundários perturbados pelas ocupações posteriores, evidenciadas no pacote estratigráfico escavado. No entanto, o achado não apresentava indicativos de percolação estratigráfica ascendente.

A indagação acima mencionada pode ser respondida analisando-se os vestígios ósseos acondicionados em laboratório, o que possibilitaria a confirmação, tanto de vestígios de práticas canibais: cortes, golpes, mordidas, polimento, quebras, raspagem e queima, (WHITE, 1992; PARKER PEARSON, 1999; TURNER II, TURNER, 1999); quanto da existência de pigmentos e tratamentos post mortem (práticas funerárias), nos fragmentos ósseos, (TORRES, 1995/1996). Da mesma forma, a escavação dos níveis mais profundos do abrigo pode demonstrar estas suposições.

Para responder, pelo menos em parte, aos questionamentos levantados, serão realizados testes nos remanescentes humanos - fragmentos ósseos e fezes 
mumificadas - e em amostras de sedimento coletadas no interior e base das estruturas de combustão. Isto vai permitir que se corrobore ou refute as hipóteses propostas: registro de práticas canibais, ou processos pós-deposicionais (perturbação) em contextos funerários, ainda não registrados no sítio.

Nesse sentido, serão realizados os testes de Fluorescência de Raios X (XRF) e Difratometria de Raio X (DRX), que indicarão, respectivamente, os elementos presentes e a composição química dos vestígios selecionados: como a presença de (1) restos de pigmento, no caso de ossos pintados; (2) hidroxiapatita, no caso de queima óssea e (3) fragmentos ósseos nas fezes mumificadas, no caso de ingestão desse tecido. Além disso, para as fezes mumificadas humanas, pretende-se realizar ainda o teste Elisa (Enzyme Linked Immunosorbent Assay), o qual, dando positivo, é indicativo do canibalismo, já que identifica a proteína mioglobina - com identificação inclusive da espécie - que está presente somente nos músculos cardíacos e esqueléticos. O teste Elisa foi utilizado num estudo arqueológico e demonstrou evidencias de canibalismo em sítios Anasazi, população pré-histórica do Sudoeste dos Estados Unidos, (MARLAR et al., 2000).

O sítio Furna do Umbuzeiro apresenta ainda um considerável pacote sedimentar preservado. O que possibilita a escavação tanto horizontal - expandindo-se para os lados a área evidenciada - quanto vertical - abaixo de $85 \mathrm{~cm}$, nível não escavado. A intervenção nesse conjunto viabiliza: a compreensão dos níveis ocupacionais já escavados no sítio; a funcionalidade do mesmo - habitacional, 
ritualístico ou ambos; bem como a possibilidade de identificação cultural dos grupos que ocuparam o abrigo.

Dessa forma, a continuação das pesquisas na Furna do Umbuzeiro contribui para a definição de enclaves pré-históricos na área arqueológica do Seridó, na medida em que possibilita testar hipóteses anteriormente levantadas: (1) acerca da identificação do primeiro sítio habitacional da região e (2) com relação à identificação de práticas canibais.

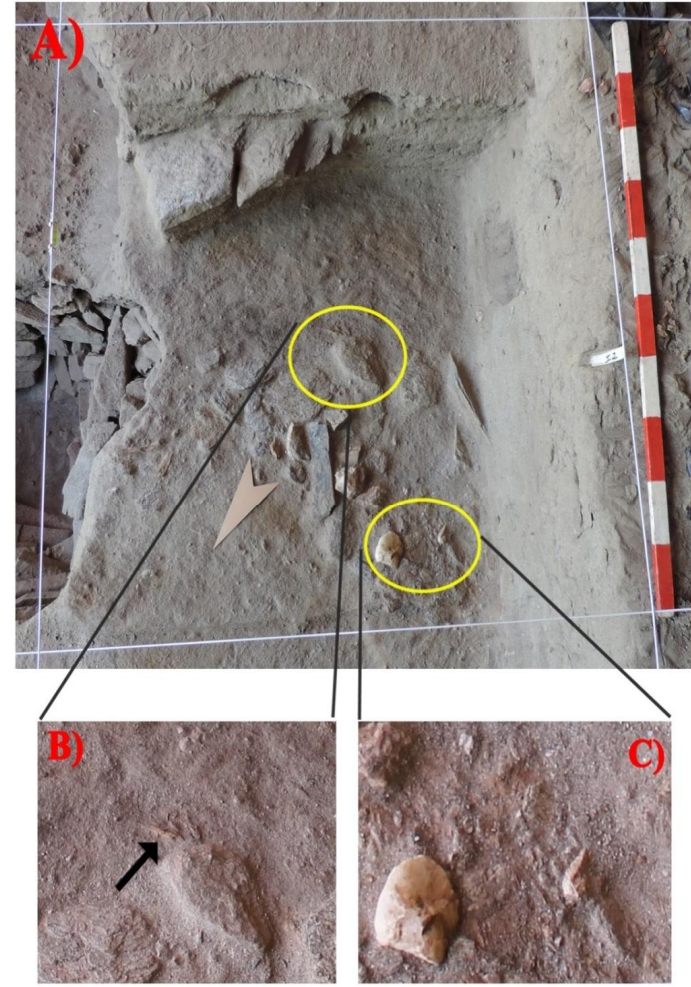

Figura 5: Quadrícula I2. A) Decapagem 7 (final $\pm 35 \mathrm{~cm}$ ); B) detalhe de fragmento de madeira; C) fragmentos de fibras vegetais manipuladas.

Indexadores: Latindex, ISIS, Google Academic 


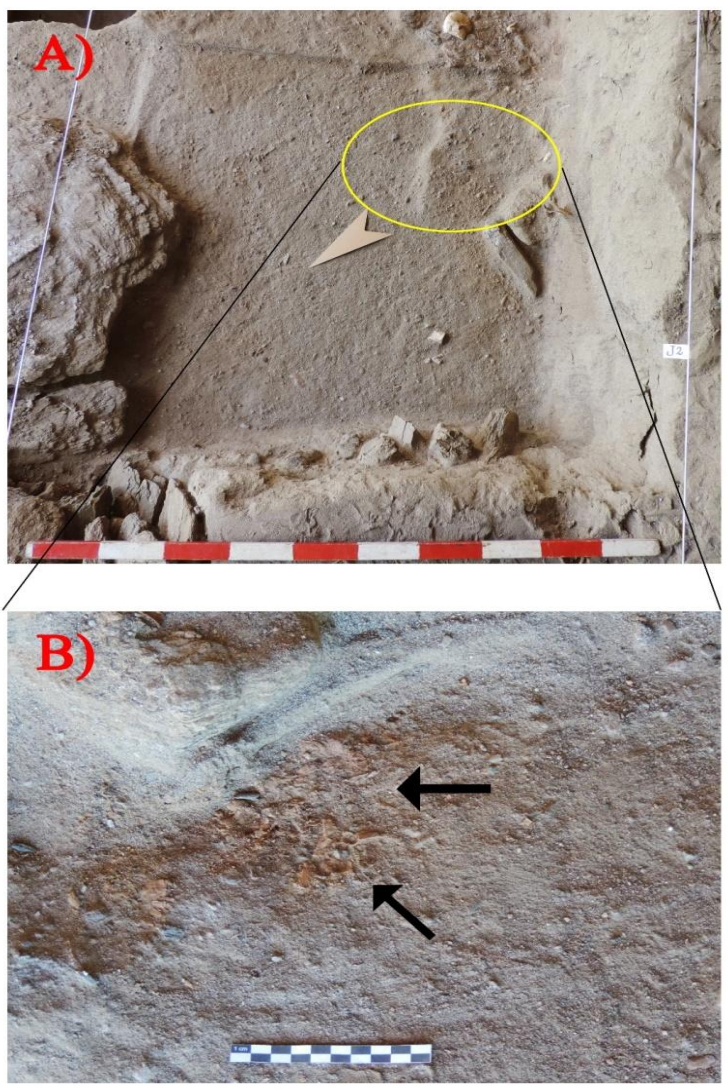

Figura 6: Quadrícula J2. A) Decapagem 8 (inicial $\pm 37,5 \mathrm{~cm}$ ); B) detalhe de fragmentos de fibras vegetais manipuladas sobre a fogueira 25 .
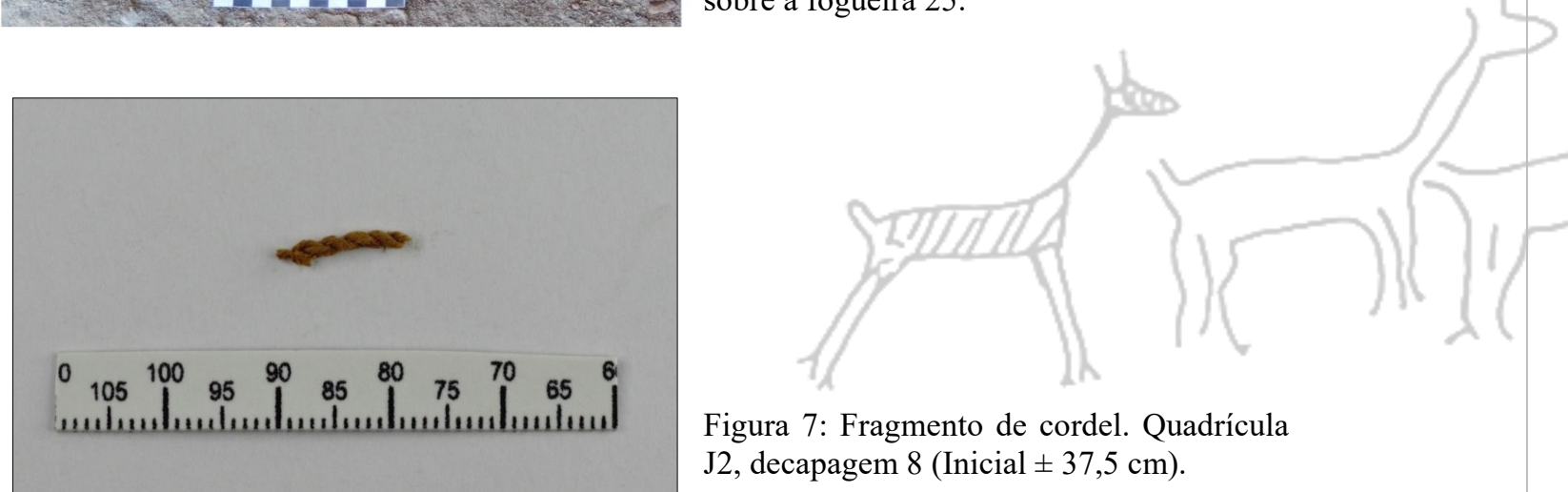

Figura 7: Fragmento de cordel. Quadrícula $\mathrm{J} 2$, decapagem 8 (Inicial $\pm 37,5 \mathrm{~cm}$ ). 


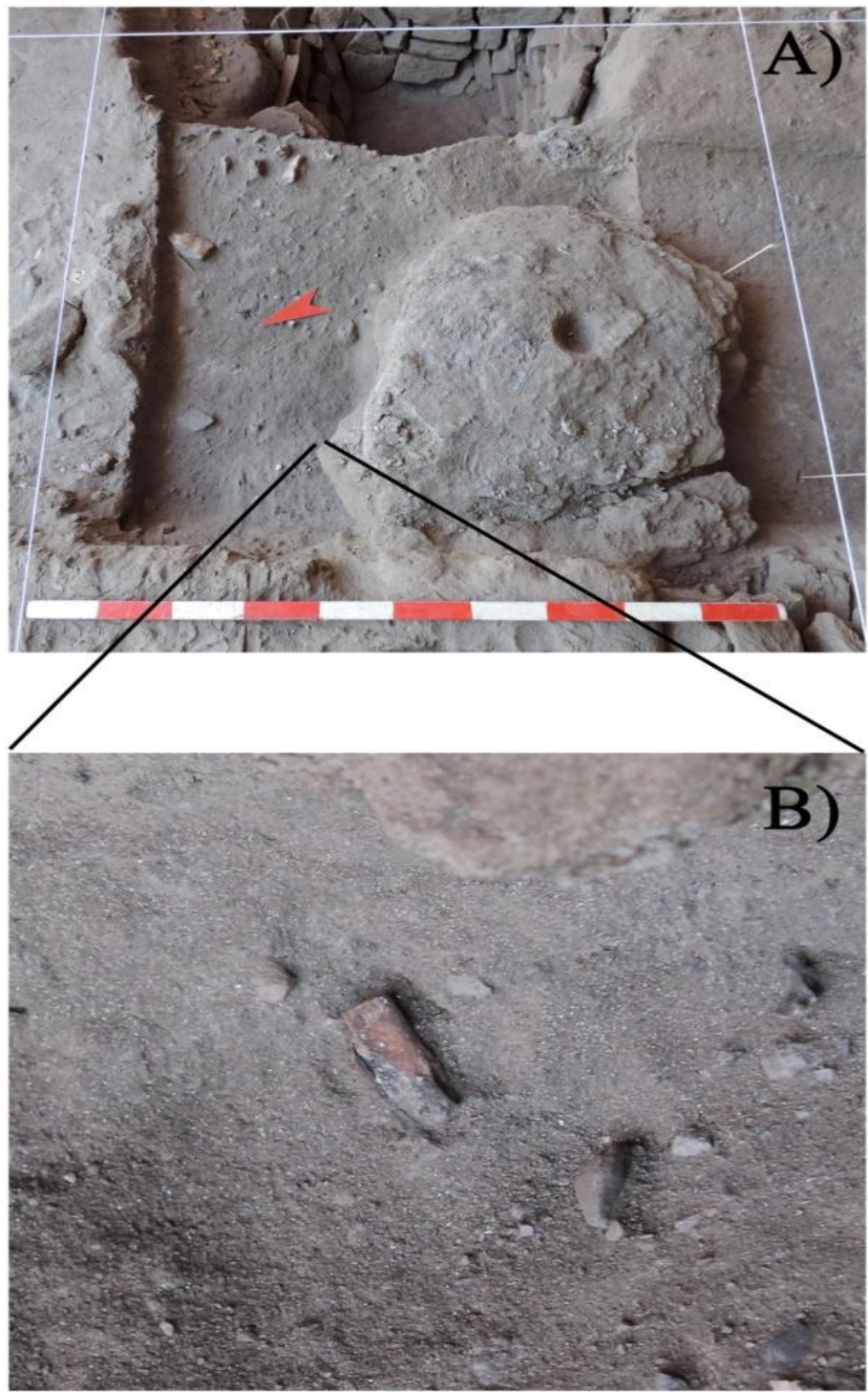

Figura 8: Quadrícula J3. A) Decapagem 6 (final $\pm 30 \mathrm{~cm}$ ); B) detalhe de um fragmento ósseo humano (costela) identificado próximo/mesmo nível da fogueira 24 , com indicativo de alteração cromática avermelhada.

Indexadores: Latindex, ISIS, Google Academic 


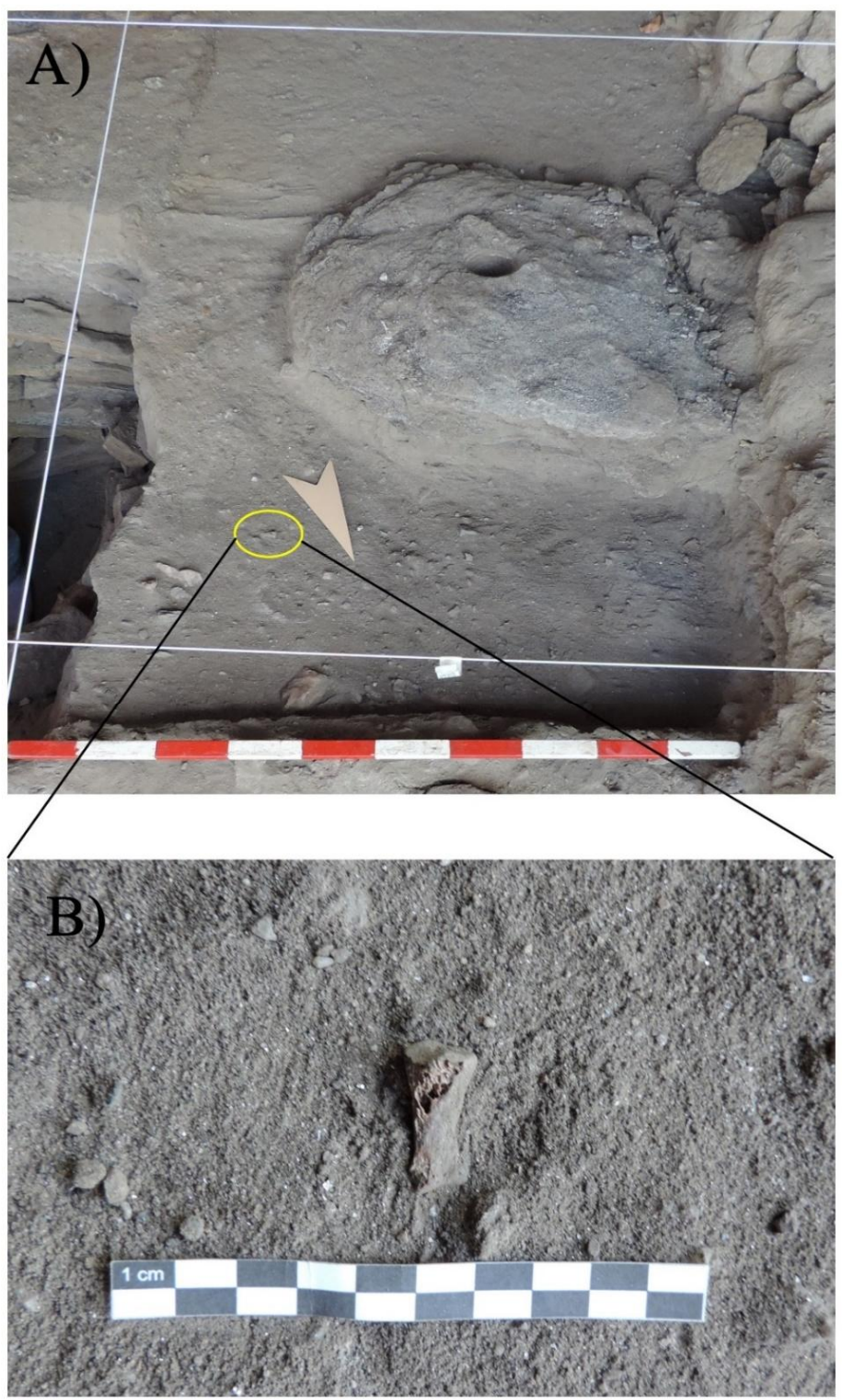

Figura 9: Quadrícula J3. A) Decapagem 6 (inicial $\pm 27,5 \mathrm{~cm}$ ); B) detalhe de um osso humano (falange) identificado na decapagem.

Indexadores: Latindex, ISIS, Google Academic 


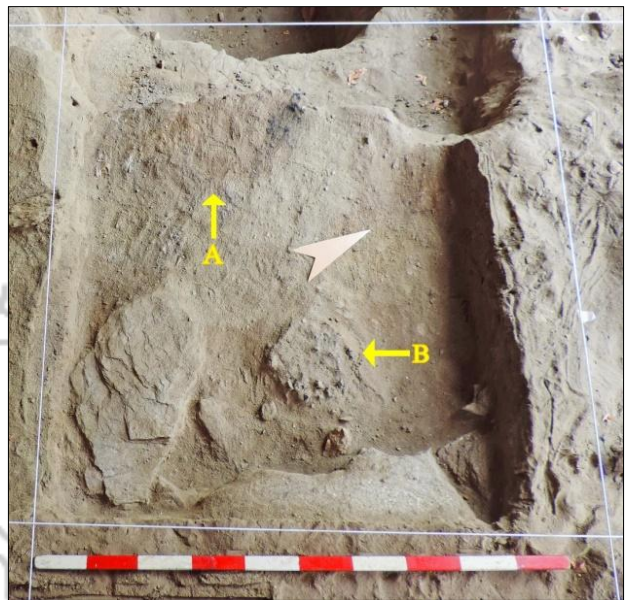

Figura 10: Quadrícula H3, decapagem 3 (final $\pm 15 \mathrm{~cm}$ ). Fogueiras indicadas pelas setas vermelhas. A - Fogueira 17; B Fogueira 23, mantida em pedestal.

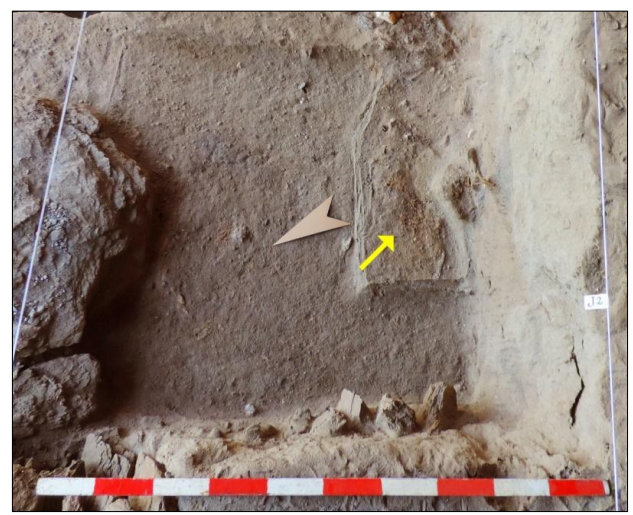

Figura 12: Quadrícula J3, decapagem 5 (final $\pm 25 \mathrm{~cm}$ ). As setas amarelas indicam a área da base das fogueiras: A - fogueira 18; $\mathrm{B}$ - fogueira 24; C - Fogueira 22.

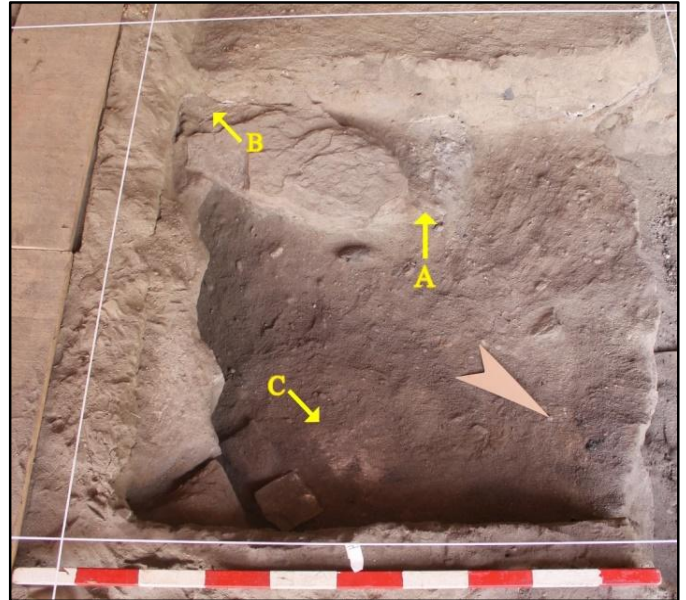

Figura 11: Quadrícula H3, decapagem 4 (inicial $\pm 17,5 \mathrm{~cm})$. Fogueiras indicadas pelas setas amarelas. A - Fogueira 17; B - Fogueira 23; C

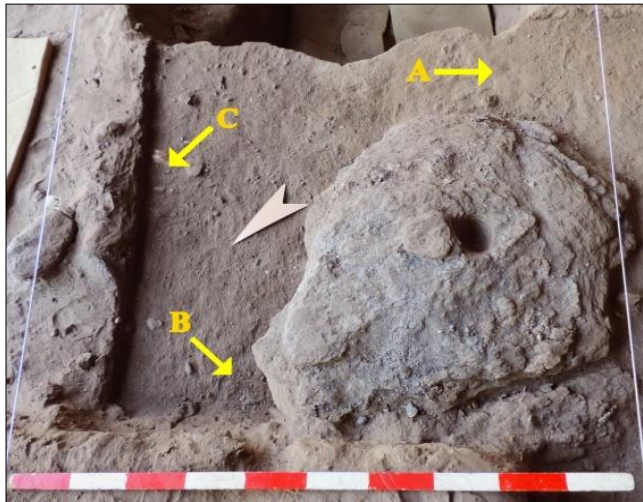

Figura 13: Quadrícula J2, decapagem 8 (final $\pm 40 \mathrm{~cm}$ ). A seta amarela indica fragmento de cestaria sobre mancha de cinzas da fogueira 25 (mantida em pedestal). 


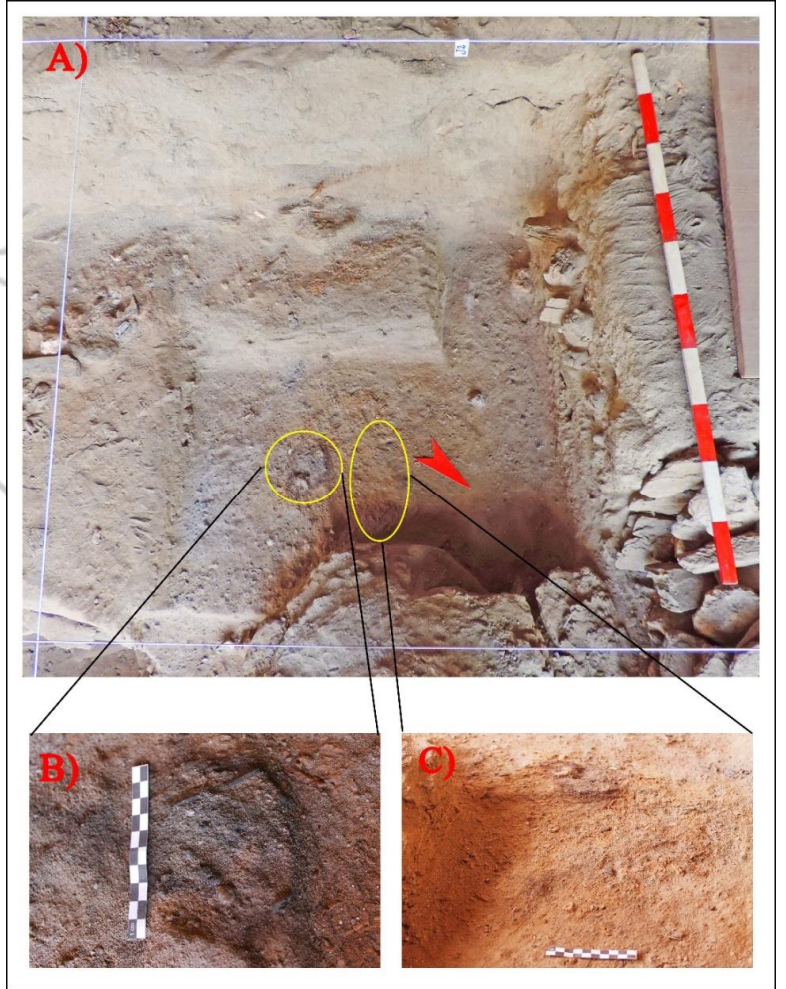

Figura 14: Quadrícula J2, decapagem 9 (final $\pm 45 \mathrm{~cm}$ ). A) Decapagem 9 (final $\pm 45 \mathrm{~cm}$ ) com pedestal; B) detalhe da fogueira 26 com sementes e fragmentos de fibra vegetal chamuscadas; C) cestaria com indícios de queima próximo a fogueira 26.

\section{REFERÊNCIAS BIBLIOGRÁFICAS}

AB'SABER, Aziz. Os domínios de natureza no Brasil: potencialidades paisagísticas. 4. ed. São Paulo: Ateliê Editorial, 2003.

AGÊNCIA NACIONAL DE ÁGUAS (ANA). Termos de referência para a elaboração do Plano de Recursos Hídricos da Bacia do Rio Piranhas-Açu - 2010. Disponível em:< http://piranhasacu.ana.gov.br/termo/TDR.pdf :>. Acesso dia: 30 set. 2016. 
BORGES, Fabio Mafra. Endocanibalismo na área arqueológica do Seridó. In: Clio Série Arqueológica, v. 1, n. 23, pp. 18-35. Recife: Editora Universitária UFPE, 2008.

BORGES, Fabio Mafra. Os sítios arqueológicos Furna do Umbuzeiro e Baixa do Umbuzeiro: caracterização de um padrão de assentamento na Área Arqueológica do Seridó - Carnaúba dos Dantas - RN, Brasil. 2010. 322 f. Tese (Doutorado em Arqueologia) - Programa de Pós-graduação em Arqueologia, UFPE, Recife: 2010.

CLASTRES, Pierre. Arqueologia da violência: pesquisas de antropologia política. Tradução de Paulo Neves. São Paulo: Cosac \& Naify, 2004.

INSTITUTO DE DESENVOLVIMENTO SUSTENTÁVEL E MEIO AMBIENTE DO RIO GRANDE DO NORTE (IDEMA); SECRETARIA DE ESTADO DO PLANEJAMENTO E DAS FINANÇAS (SEPLAN). Perfil do município de Carnaúba dos Dantas - 2008.2 Disponível em: $<$ http://adcon.rn.gov.br/ACERVO/idema/DOC/DOC000000000016640.PDF:>. Acesso dia: 10 out. 2016.

MAFRA, Fábio; MARTIN, Gabriela; NOGUEIRA, Mônica. Intervenções arqueológicas em sítios a céu aberto na área arqueológica do Seridó: os sítios Meggers I e Meggers III, Parelhas - RN, Brasil. In: Clio - Série Arqueológica, v. 30, n. 1, p. 10-37. Recife: Editora Universitária UFPE, 2015.

MAFRA, Fábio; MARTIN, Gabriela; NOGUEIRA, Mônica. Sítios a céu aberto na região do Seridó Potiguar: um estudo de caso do Rio da Cobra, entre os municípios de Carnaúba dos Dantas e Parelhas - RN. In: Clio - Série Arqueológica, v. 31, n. 3, p. 113-132. Recife: Editora Universitária UFPE, 2016.

MARLAR, R. A.; LEONARD, B.L.; BILLMAN, B.R.; LAMBERT, P.M.; MARLAR, J.E. Biochemical evidence of cannibalism at a prehistoric Puebloan site in southwestern Colorado. Nature, v. 407, n. 6800, p. 74-78. Londres: Macmillian Magazines, 2000.

MARTIN, Gabriela. Pré-história do Nordeste do Brasil. 5. ed. Recife: Editora Universitária da UFPE, 2008.

MARTIN, Gabriela; BORGES, Fabio Mafra; SENA, Vivian Karla de; SALDANHA, Rafael S. Medeiros; ALMEIDA, Marcellus; NOGUEIRA, Mônica A. Araújo; 
BARBOSA, Caio C. Araújo. Levantamento arqueológico na área arqueológica do Seridó - Rio Grande do Norte - Brasil: nota prévia. In: Clio - Série Arqueológica, v. 2, n. 23, p. 01-09. Recife: Editora Universitária UFPE, 2008.

MEDEIROS FILHO, Olavo de. Índios do Açu e Seridó. Brasília: Centro Gráfico do Senado Federal, 1984.

NOGUEIRA, Mônica; MAFRA, Fabio. Levantamento de sítios arqueológicos a céu aberto na área arqueológica do Seridó - Rio Grande do Norte - Brasil. In: Mneme Revista de Humanidades, v. 15, n. 35, pp. 244-259. Caicó: CERES/UFRN, 2014.

PARKER PEARSON, Mike. The archaeology of death and burial. Texas: Texas A\&M University Press, 1999.

RAMALHO, Moisés. Os Yanomami e a morte. 2008. 168f. Tese (doutorado em Antropologia) - Programa de Pós-graduação em Antropologia Social, USP, São Paulo: 2008.

SUPERINTENDÊNCIA DO DESENVOLVIMENTO DO NORDESTE (SUDENE). Carta topográfica. Folha Jardim do Seridó. SB. 24-Z-B-V. Recife: SUDENE, 1985. Escala 1: 100.000

TORRES, Ana Catarina. Estudo dos pigmentos do sítio pré-histórico Pedra do Alexandre - Carnaúba dos Dantas - RN. In: Clio - Série Arqueológica, v. 1, n. 11, p. 59-70. Recife: Editora Universitária UFPE, 1995/1996.

TURNER II, C. G; TURNER, J. A. Man Corn: cannibalism and violence in the prehistoric American Southwest and Mexico. Salt Lake City: University of Utah Press, 1999.

WHITE, Tim D. Prehistoric cannibalism at Mancos 5MTUMR-2346. Princeton: Princeton University Press, 1992. 